descriptions of many things (see, for example, the description of fluorescence microscopy).

One gripe is that the authors have, for the most part, left out the one thing that nonexperts can never know - what is not known. An expert will find examples on every page where the facts are not yet in or are contradictory. Yet phrases like "still not known" and "unclear how" are few and far between. A textbook writer cannot leave a trail of uncertainty for a novice reader, but the next generation of biologists deserves to know more about the soft spots in our knowledge, if only to provide food for thought about future contributions. One simple way to do this would be to distinguish more clearly which illustrations are models and which are established facts.

The inevitable question is how does Molecular Cell Biology II compare with Molecular Biology of the Cell II by Alberts et al. (Garland, 1989)? Both are authori-

\section{A useful addition}

\section{Harry Cotton}

Computing Before Computers. Edited by William Aspray. Iowa State University Press: 1990. Pp. 266. \$27.95.

IF YOUR grasp of computer history starts with microcomputers, this book should demonstrate that there was computing life before electronic digital machines. Others whose knowledge is broader will find here new topics along with the familiar. You may know about Roman numerals, but have you seen additions and multiplications fully worked through in them?

For many people, early computing means the abacus, logarithms, slide-rules and Babbage. They are all here. But there are surprises - the chapter on Babbage scotches the widely held belief that Ada Lovelace was the first programmer. It is implied that the work she did for Babbage was not original programming. If women programmers, trying to combat the male dominance in their profession, need a role-model, it may have to be the much later Grace Hopper of the US Navy (coiner of the term "bug").

The period from Babbage until about 1950 , which is often a blank in computing history even for computer people, is well documented in Computing Before Computing. One example is the discussion of why valves did not replace relays at an earlier stage in the design of computing equipment. It is paradoxical that a device as inherently unreliable as a valve should ultimately supersede the more robust relay. By running valves at well below their limits and never switching off their tative, up to date and beautifully produced. The latter is more consistent in approach and style, and its authors make more effort to point out gaps in our knowledge. It is 13 per cent longer and packs more detailed information into its diagrams. But the former makes a better job of integration across the biological kingdoms. One could build an excellent course around either book. As in art, the decision is a matter of taste.

Thomas D. Pollard is in the Department of Cell Biology and Anatomy, Johns Hopkins University Medical School, Baltimore, Maryland 21205, USA.

- For review of the first edition, see Nature 323, 401; 1986. Molecular Biology of the Cell was reviewed in Nature 302, 637; 1983 and its second edition in Nature 340, 608; 1989. - Published on 10 August is A Student's Companion to Molecular Cell Biology, by D. Rintoul et al. Again, publisher is Scientific American Books: price is $£ 14.95, \$ 17.95$ pbk.

heaters, reliability was improved. Valves usually burn out totally so engineers know when there is something wrong and where the correction has to be made. Finally, the greatly increased speed of operation of valve equipment over relays won the day. The rule about not switching off valve machines was not well-learned, however, as the first programmers found when they faced a digital computer on a Monday morning.

With five authors (including the editor) sharing seven chapters, style and content of this volume vary. What may interest one reader may be a subject for skipping by another, and it is unlikely that any one will find all subjects of equal merit. Topics range from early calculation through a variety of calculating machinery, including analogue computers, to relay and electronic calculators. Information given about work on computing equipment in Germany during World War II will be new to most readers. It offers some contrast with the British code-breaking computer, Colossus, built about the same time.

Occasional algebraic formulae or smidgeons of calculus are to be found here, especially in the section on the difference engine and the chapter on analogue computers. Few users of digital computers feel comfortable with the concepts of analogue computing, perhaps because no two analogue computers ever seem to be alike.

The inclusion of a chapter on punchedcard machinery might seem to be a diversion, and yet this technology played a significant part in paving the way for digital computers as the manufacturing companies involved formed the nuclei of the emergent computer industry. Quaintlooking punched-card readers were modernized by having their wrought-iron legs hastily covered up by metal boxes and were adapted as data-input devices Tabulators were modified to become the high-speed printers that computers needed if they were to be of value to the commercial user. But there was a long interval before computers (which were first used for scientific work) could take over the jobs done by punched-card machinery, and there was a further period when both types of equipment were used side-by-side and even offered in competition in the one bid. It is interesting to realize that punched-cards were used for scientific calculations despite their obvious bias towards mundane statistical and commercial applications.

Scientific and technological history is often presented as a string of success stories. This example of the genre is a salutary reminder that for every one success there were many failures. Most of the equipment described in this book was never finished or, if it was, never worked with any consistency. The authors conclude that, despite some similarities in general concepts, early computer equipment has contributed little to present designs.

Progress in computing since this history ends has been rapid. The book contains a photograph, courtesy of the Smithsonian Institute, of a slide-rule. For those of us who still own such an object, not yet in a museum, the caption is a measure of that progress and, perhaps, our own advancing years.

Harry Cotton is at 37 Penrhyn Avenue, Alkrington, Middleton, Manchester M24 1FP, UK.

\section{New in paperback}

- The latest collection of discourses from the Royal Institution has been published by Science Reviews Ltd as volume 61 of the Proceedings of the Royal Institution. The book contains short, readable reviews on physics and music, making muscles move, antimatter enzymes and other topics. Price is $£ 28, \$ 26$.

- Theoretical Population Genetics by J. S. Gale explains the neutral theory of evolution to nonmathematical biologists. Published by Unwin Hyman, price is $£ 17.95$ (also available in hardback at $£ 50$ ).

- Adrian Desmond's The Hot-Blooded Dinosaurs, was originally published in 1975 , this edition is published by Hutchison as a Radius paperback at $£ 7.99$ on 6th September. After the success of this book, Dr Desmond became a full-time writer. His most recent book, The Politics of Evolution was reviewed in Nature 344, 485; 1990 by Sir Christopher Booth.

- Butterworths has recently published The Chemistry of Hydrocarbon Fuels by $\mathrm{H}$. H. Schobert. The book provides an introduction to the chemistry of petroleum, natural gas and coal. Price is $\$ 35$.

- Recently published by Oxford University Press is The Mathematics of Games by John Beasley. The author shows how simple mathematical analysis can throw unexpected light on games such as poker, golf, cricket, solitaire and Rubik's cube. Price is $£ 5.95$. 